\title{
The development of anti-HLA antibodies in multiply transfused preterm infants
}

\author{
Alison R Bedford Russell, Rodney P A Rivers, Nicholas Davey
}

\begin{abstract}
The development of antihuman leucocyte antigen antibodies (aHLAA) in response to multiple transfusions in preterm infants was studied prospectively. Fifty seven infants requiring a minimum of two blood transfusions were recruited after obtaining informed written parental consent. They were randomised to receive either whole blood or blood that had been passed through a leucocyte filter. Anti-HLAA were sought in maternal and cord blood so as to ensure that any aHLAA detected after transfusion had not been passively transferred antenatally, and in $1 \mathrm{ml}$ samples drawn monthly from the baby, at least 10 days from a previous transfusion, until discharge from hospital. Anti-HLAA were detected by microlymphocytotoxicity assay. Results were obtained in 42 babies, 19 in the filter and 23 in the no filter group. Fifteen babies had to be excluded because of protocol violation or because they died. None of the babies receiving filtered blood developed aHLAA, but seven babies in the no filter group developed aHLAA.

In conclusion, multiply transfused preterm infants have the ability to elaborate antibodies to HLA and leucocyte filters may prevent this.
\end{abstract}

(Arch Dis Child 1993;68:49-51)

It is recognised that leucocyte antigens present in transfused whole blood are responsible for complications, including non-haemolytic febrile transfusion reactions, in multiply transfused individuals. ${ }^{1-4}$

The use of leucocyte depleted blood markedly reduces the incidence of sensitisation to leucocyte antigens. ${ }^{1}$ This is most easily achieved at the bedside by administering blood through a blood administration set to which a leucocyte removal filter has been attached. ${ }^{5}$

The ability of neonates to produce significant antibody concentrations is limited. B lymphocytes in cord blood of normal full term neonates are functionally immature having a reduced capacity to secrete immunoglobulins. ${ }^{6}$ At birth there is a linear relationship between $\log$ IgG and gestational age, most of the IgG being transferred transplacentally. ${ }^{7}$ Immunoglobulin synthesis in neonates is mostly of the IgM class, but cord IgM may be undetectable especially in babies less than
32 weeks' gestation. ${ }^{7}$ A previous study of multiply transfused infants failed to detect red cell antibodies in 53 infants and leucocyte antibodies in 13 infants. ${ }^{8}$

Febrile reactions to blood transfusions have been documented in infants beyond the neonatal period, ${ }^{1}$ and an 18 day old infant who produced alloanti-E antibodies has been reported. ${ }^{9}$

In this study HLA antibody production and the efficacy of a leucocyte filter in preventing sensitisation, were prospectively studied in a group of multiply transfused preterm infants.

\section{Patients and methods}

\section{PATIENTS}

Babies <37 weeks' gestation admitted to the neonatal unit and likely to receive two or more blood transfusions were recruited with their mothers after obtaining informed written parental consent. They were randomised to receive either filtered or unfiltered blood. Randomisation was by using random number tables and placing a card with the designated group in a sequentially numbered envelope. Babies were not recruited if there was no parental consent or if their mothers were in a group at high risk of infection. Babies were subsequently excluded if they died in the neonatal period or if those randomised to receive filtered blood received exchange, leucocyte, or platelet transfusions.

\section{PROCEDURES}

One to $5 \mathrm{ml}$ of cord blood and $5 \mathrm{ml}$ of maternal blood were collected for baseline measurement of antihuman leucocyte antigen antibodies (aHLAA). Follow up blood samples of $1 \mathrm{ml}$ were collected from infants as near to monthly intervals as possible. Collection was delayed if transfusion had occurred $<10$ days previously to negate the detection of passively transferred antibody. All blood was collected into additive free tubes. Babies were studied until they no longer required routine venesection as all blood samples were obtained at this time.

All babies received red cell concentrations that had been passed through the standard blood administration set with integral $170 \mu \mathrm{m}$ filter. In addition babies randomised to the filter group received blood passed through an 'in-line' leucocyte microfilter to render it leucocyte (and platelet) poor. The filter was composed of non-woven polyester in an acrylonitrilestyrene copolymer container, and was adapted from the standard Sepacell 
leucocyte filter for small volumes of blood (Kimal Scientific Products Ltd).

ASSAYS

Sera were collected after centrifugation of blood samples and stored at $-20^{\circ} \mathrm{C}$ until the assays were performed in the department of immunology, Hammersmith Hospital. AntiHLA antibodies in the sera were detected by conventional microlymphocytotoxicity testing based upon the method originally described by Terasaki and McClelland. ${ }^{10}$ Briefly, sera were incubated with a panel of 50 well characterised human lymphocytes of known HLA phenotypes and covering all common HLA specificities. After the addition of rabbit complement (Buxted Rabbit Co Ltd), cells were assessed for viability by the addition of a double fluorochrome cocktail containing 0.5 $\mathrm{mg} / \mathrm{ml}$ propidium iodide (Sigma; $\mathrm{p}-4170$ ), 0.5 $\mathrm{mg} / \mathrm{ml}$ acridine orange (BDH; 34001), 0.5\% w/v disodium EDTA (BDH; 28025), and 2\% $\mathrm{v} / \mathrm{v}$ drawing ink (Faber Castell; TG1) in phosphate buffered saline. Cell death assessment was by semiautomated fluorescent microscopy. In all cases these tests were performed 'blind' in that the category to which the baby was randomised was unknown.

For each test the degree of complement mediated cytotoxicity was scored on a linear scale from $0-8 ; 0$ being negative $(>99 \%$ viability) while a score of 8 was assigned to strong positive reactions with $>80 \%$ cells killed. A test was considered to be positive where the serum gave a score of $>2(20 \%$ cells killed). Scores of $<2$, but that were above the background value, were considered to be negative unless the same sera also gave clear and reproducible positive results with at least one other cell.

Table 1 Details of patients in the two groups. Results are median (range)

\begin{tabular}{lcc}
\hline & $\begin{array}{l}\text { Filter } \\
(n=19)\end{array}$ & $\begin{array}{l}\text { No filter } \\
(n=23)\end{array}$ \\
\hline Gestation (weeks) & $29(24-35)$ & $29(24-36)$ \\
Weight $(\mathrm{g})$ & $950(675-2240)$ & $1200(650-3020)$ \\
No of transfusions & $8(2-35)$ & $4(2-22)$ \\
Follow up time (months) & $2(1-6)$ & $2(1-6)$ \\
\hline
\end{tabular}

Table 2 Characteristics of the seven anti-HLA antibody positive babies in the no filter group

\begin{tabular}{|c|c|c|c|c|c|c|c|c|c|}
\hline \multirow{2}{*}{$\begin{array}{l}\text { Gestation } \\
\text { (weeks) }\end{array}$} & \multirow{2}{*}{$\begin{array}{l}\text { Weight } \\
(g)\end{array}$} & \multirow{2}{*}{$\begin{array}{l}\text { No of } \\
\text { transfusions }\end{array}$} & \multicolumn{7}{|c|}{ Months after transfusion } \\
\hline & & & of & 1 & 2 & 3 & 4 & 5 & 6 \\
\hline 27 & 1005 & 3 & - & - & $\begin{array}{l}+ \\
(\mathrm{m})\end{array}$ & & & & $\stackrel{+}{(\mathrm{m})}$ \\
\hline 28 & 1400 & 5 & $\stackrel{+}{(\mathrm{B} 5 / \mathrm{B} 7)}$ & $\stackrel{+}{(\mathrm{A} 10)}$ & & & & & \\
\hline 29 & 996 & 3 & - & $\begin{array}{l}+ \\
\text { (B7) }\end{array}$ & & $\stackrel{+}{(\mathrm{A} 3)}$ & - & & \\
\hline 32 & 2300 & 17 & - & $\begin{array}{l}+ \\
(\mathrm{m})\end{array}$ & $\begin{array}{l}+ \\
(\mathrm{m})\end{array}$ & $\begin{array}{l}+ \\
(\mathrm{m})\end{array}$ & $\stackrel{+}{(m)}$ & & \\
\hline 32 & 1896 & 2 & - & $\begin{array}{l}+ \\
\text { (A32) }\end{array}$ & & & & & \\
\hline 33 & 1513 & 4 & - & $\begin{array}{l}+ \\
\text { (B17) }\end{array}$ & & - & & & \\
\hline 36 & 2500 & 3 & - & $\stackrel{+}{(\mathrm{A} 1 / \mathrm{B} 6)}$ & & & - & & - \\
\hline
\end{tabular}

:Anti-HLA antibody type in brackets; $+=$ positive; - =negative; $\mathrm{m}=$ formation of multispecific antibodies.

t0 $=$ cord blood result
STATISTICS

Results were analysed using Fisher's exact test; $p$ values represent the approximate two sided probability values.

ETHICAL APPROVAL

Approval was obtained from the district medical ethics committees of the Parkside and the Wandsworth district health authorities.

\section{Results}

FILTER EVALUATION

The average red cell recovery was $99 \%$ (range $95 \cdot 7-100 \%, n=10)$ and the residual absolute white cell count $0 \cdot 2 \times 10^{9} / 1$ (range $0 \cdot 1-0 \cdot 3$ $\times 10^{9} / 1 ; n=10$ ). Counts were performed on the standard laboratory Coulter counter and the films checked manually.

\section{PATIENTS}

Fifty seven babies were recruited and results were available for 42,19 randomised to receive filtered blood and 23 to receive unfiltered blood. Thirty nine babies were recruited at St Mary's and 18 at St George's. Of those recruited, 10 died, three randomised to receive filtered blood received unfiltered blood, and two were transferred back to their referring hospitals before follow up samples could be collected.

The median and range of values for gestational age, weight, number of transfusions, and follow up time in each group are shown in table 1 .

Anti-HLAA were detected in the sera from mothers but not the corresponding cords in six cases randomised to the no filter group. The cord blood from a further three babies in this group (two of whom were twins), were positive for aHLAA, but sera from their mothers were not obtained. One of these babies subsequently developed aHLAA of a different specificity in response to multiple transfusion; the antibodies had disappeared in the other two babies a month later. In the filter group six of the mothers were shown to have aHLAA, and the cord blood of one of their babies had the corresponding antibody, which was undetectable in the baby one month later.

Seven babies in the no filter group developed positive aHLAA, not present in cord blood, but all 23 babies in the filter group were HLA antibody negative on testing $(p=0.0182$ by Fisher's exact test, two tailed analysis). The characteristics of the anti-HLA antibody positive babies are shown in table 2 .

\section{Discussion}

The results of this study show that multiply transfused babies can produce anti-HLA antibodies, although their presence in serum may only be transient. HLA antigens are otherwise known as the major histocompatibility complex antigens, and are the most important in determining the compatibility of tissue grafts. HLA-A, HLA-B, and HLA-C antigens are present on platelets and all nucleated cells 
except placental trophoblasts and spermatozoa. It is these antigens, present on T lymphocytes, that are detected in the microlymphocytotoxicity assay. The DR antigens have a distribution restricted to B lymphocytes, monocytes, and epidermal cells. ${ }^{1}$

Anti-HLAA frequently develop in patients having blood transfusions from many different donors, but can develop after just a single transfusion, being more frequently formed when the transfusion is massive, for example in patients undergoing open heart surgery. ${ }^{1}$ It is therefore not surprising that the babies developing aHLAA did so after as few as two transfusions. The baby who received 17 transfusions was strongly positive for aHLAA.

Anti-HLA antibodies also develop in pregnancy and while aHLAA induced in response to paternal haplotypes are not found in the cord blood of a current pregnancy, those induced by other mechanisms, for example previous pregnancy or blood transfusion, can be found. ${ }^{11}$ Baseline measurements of aHLAA in mothers and their infants were therefore important. Only one baby in this study, in whom aHLAA were detected in the cord serum, subsequently developed a different antibody in response to multiple transfusion.

Some adults and older children are nonspecifically unresponsive to HLA and fail to develop aHLAA in response to multiple blood transfusions. The reasons for this remain unclear. ${ }^{12}$ This inability of some individuals to respond to HLA may explain why only some infants in the no filter group developed aHLAA, although immaturity of the immune system may have a role. ${ }^{13}$

Characteristically aHLAA are of the IgG class and have complement fixing and agglutinating properties. The antibodies detected in our study could have been of the IgM class, as would be expected in preterm neonates, but due to limited availability of sera we were unable to make this distinction.

When HLA are expressed on the cell membrane surface of red blood cells, the development of corresponding antibodies has been shown to be responsible for haemolytic transfusion reactions and very short red blood cell survival. ${ }^{14}$ It is a matter of speculation as to whether this mechanism of shortened survival is a contributory factor in multiply transfused neonates who fail to sustain a satisfactory rise in haemoglobin after blood transfusion.

The Department of Health guidelines state that 'all blood components must be infused through a set containing an integral filter $(170 \mu \mathrm{m})$ to trap large aggregates'. ${ }^{15}$ This practice is not strictly adhered to on all neonatal units and blood is sometimes drawn straight from the bag with a needle and syringe. Microaggregate filters of $20-40 \mu \mathrm{m}$ size, similar to the Sepacell filter (pore size $40 \mu \mathrm{m}$ ), trap small aggregates of leucocytes and platelets that form in blood stored beyond five days. Their benefit in routine neonatal transfusion has been a matter for debate, ${ }^{16-18}$ but their use has been advocated for large transfusions and blood stored for more than five days. ${ }^{15} 19$ In addition to their role as microaggregate filters, leucocyte filters are of benefit where the blood supplied for neonatal transfusion is not guaranteed to be cytomegalovirus free. ${ }^{20}$

In conclusion we have shown that some preterm infants have the ability to produce aHLAA in response to multiple blood transfusions and that the use of leucocyte depleted blood prevents this development. In addition, use of a leucocyte filter has the benefits of a microaggregate filter and may prevent transfusion-acquired cytomegalovirus infection.

We are grateful to Dr H Dodsworth (consultant haematologist, St Mary's Hospital) for her assistance with the design modification of the Sepacell filter.

AR Bedford Russell was generously supported by the $S t$ AR Bedford Russell was generously supported by the St
Mary's Save The Baby Fund. Leucocyte filters and assistance Mary's Save The Baby Fund. Leucocyte filters and assistance
with laboratory costs were provided by Kimal Scientific Products Ltd.

The laboratory work was carried out in the Sam Segal Perinatal Unit, St Mary's Hospital, and at the department of immunology, Hammersmith Hospital.

Babies were recruited from the neonatal units at St Mary's and St George's Hospitals.

Mollison PL. Blood transfusion in clinical medicine. 8th Ed. Oxford: Blackwell, 1987.

Barton JC. Nonhaemolytic, noninfectious transfusion reactions. Semin Hematol 1981;18:95-121.

3 Herzig RH, Herzig GP, Bull MI, et al. Correction of poor platelet transfusion responses with leukocyte-poor HLAmatched platelet concentrates. Blood 1975;46:743-50.

4 Gascon P, Zoumbos NC, Young NS. Immunologic abnormalities in patients receiving multiple blood transfusions. Ann Intern Med 1984;100:173-7.

5 Sirchia G, Rebulla P, Parravicini A, et al. Leukocyte depletion of red cell units at the bedside by transfusion through a new filter. Transfusion 1987;27:402-5.

6 Lucivero G, Dell'Osso A, Iannone A, et al. Phenotypic immaturity of $\mathrm{T}$ and $\mathrm{B}$ lymphocytes in cord blood of fullterm normal neonates. Biol Neonate 1983;44:303-8.

7 Evans HE, Akpata SO, Gkass L. Serum immunoglobulin levels in premature and full-term infants. $\mathrm{Am} 7 \mathrm{Clin}$ levels in premature and

8 Floss AM, Strauss RG, Goeken N, Knowx L. Multiple transfusions fail to provoke antibodies against blood cell antigens in human infants. Transfusion 1986;26:419-22.

9 Smith MR, Storey CG. Allo-anti-E in an 18-day old infant. Transfusion 1984;24:540.

10 Terasaki PI, McClelland JD. Microdroplet assay of human serum cytotoxins. Nature 1964;204:998-1000.

11 Tongio MM, Mayers S, Lebec A. Transfer of HL-A antibodies from the mother to the child. Transplantation 1975;20:163-6.

12 Opelz G, Mickey MR, Terasaki PI. Identification of unresponsive kidney transplant recipients. Lancet 1972;i: 868-71.

13 Hayward HR. Development of lymphocyte responses and interactions in the human fetus and newborn. Immunol interactions in the
$\operatorname{Rev} 1981 ; 57: 39-60$.

14 Panzer S, Mayr WR, Graninger W, et al. Haemolytic transfusion reactions due to HLA antibodies. Lancet 1987 i:474-8.

15 McClelland DBL. Handbook of transfusion medicine. London: HMSO, 1989:32.

16 Longhurst DM, Gooch III WM, Castillo RA. In vitro evaluation of a pediatric microaggregate blood filter Transfusion 1983;23:170-2.

17 Sinko GE. Microaggregate filters and neonatal patients. Transfusion 1983;23:537-8.

18 Plotz RD. Neonatal pulmonary microaggregates and thrombi. Am $\mathcal{F}$ Clin Pathol 1987;87:380-3.

19 Takaori M, Nakajo N, Ishii T. Changes of pulmonary function following transfusion of stored blood. Transfusion 1977;17:615-20.

20 Gilbert GL, Hudson IL, Hayes K, James J. Prevention of transfusion acquired cytomegalovirus infection in infants by blood filtration to remove leucocytes. Lancet 1989; 1228-31. 